\title{
Occult Bladder Perforation with Atypical Localization: A Complication of Laparoscopic Burch Colposuspension
}

\author{
Kinay T*, Ensari T1, Unsal M1, Ackkgoz $\mathrm{O}^{2}$, \\ Altinbas $\mathrm{SK}^{1}$ and Tapisiz $\mathrm{OL}^{1}$ \\ ${ }^{1}$ Department of Gynecology and Obstetrics, University of \\ Health Sciences, Turkey \\ ${ }^{2}$ Department of Urology, University of Health Sciences, \\ Turkey \\ *Corresponding author: Kinay Tugba, Department of \\ Obstetrics and Gynecology, University of Health Sciences, \\ Etlik Zubeyde Hanim Women's Health Training and \\ Research Hospital, Yeni Etlik Cd, Ankara, Turkey
}

Received: November 15, 2017; Accepted: December 08, 2017; Published: December 15, 2017

\begin{abstract}
Background: Laparoscopic Burch colposuspension is an effective surgical treatment option for stres urinary incontinence. Complication rates are low and similar with open technique. Bladder perforation is one of the complications.

Case: A 46-year old, para 2 woman with stress urinary incontinence underwent laparoscopic Burch colposuspension. Abdominal pain, nausea and urine output reduced was emerged on the second postoperative day. Bladder perforation with atypical localization was detected with cystoscopy and diagnostic laparoscopy. The defect was repaired via laparoscopic sutures.

Conclusion: Bladder perforation with atypical localization may occur due to laparoscopic Burch colposuspension. Diagnostic laparoscopy with a careful cystoscopy examination is useful in the diagnosis. Laparoscopy is also convenient approach for the management of complications.
\end{abstract}

Keywords: Laparoscopic Burch colposuspension; Complication; Laparoscopy

\section{Background}

Laparoscopic Burch colposuspension is an effective treatment modality for stress urinary incontinence [1]. The success rate of laparoscopic technique is similar to open colposuspension and sling operations $[2,3]$. Complication rates of laparoscopic and open techniques are also comparable [4]. In this report, we present a case who had occult bladder perforation with atypical localization occurred after laparoscopic Burch colposuspension.

\section{Case Presentation}

A 46-year-old, gravida 2, para 2 woman had ovarian endometrioma and stress urinary incontinence. Laparoscopic unilateral salpingoophorectomy and laparoscopic Burch colposuspension via intraperitoneal route was performed concomitantly. No pathology was detected in cystoscopy examination intraoperatively. A total of $2,000 \mathrm{~mL}$ urine output was noted, and no hematuria was detected on the first postoperative day. The urinary catheter was removed on the $24^{\text {th }}$ postoperative hour. On the second postoperative day, the patient had a complaint of worsening abdominal pain with nausea, and urine output reduced. The abdomen was distended and tender, subcutaneous edema was present. An abdominopelvic ultrasound scan revealed a distended Retzius area filled with fluid suggestive of urine. A sample of the fluid confirmed urine. Urine accumulation in the Retzius space did not reduce despite the bladder catheterization on the $3^{\text {rd }}$ postoperative day. Via a percutaneous approach, a catheter was inserted in the area. As increasing amounts of urine coming from Retzius space was detected on the next 5 days of follow-up, the patient was taken to the operating theatre for a concomitantly performed cystoscopy and diagnostic laparoscopy. A- 1, 5cm atypical defect localized on the right anterolateral wall of the bladder was observed (Figure 1). The right-sided sutures inserted into the paravaginal fascia in the first operation were free from their areas. Bladder catheterization did not work, because the defect adjacent to the right paraureteral space caused an immediate drainage of the urine to the Retzius space. A suture passing through the serosa of the bladder was thought to cause the perforation of the bladder. After removal of the Foley catheter, probable tension created by the sutures during filling and emptying movements of the bladder led to laceration of the bladder wall. Free sutures on the right side were removed, and the defect was repaired via laparoscopic sutures (Figure 2). The Foley catheter was removed on the 10th postoperative day. For two months after the operation and clinical evaluations at 2, 4, and 6 months postoperatively confirmed an improvement in incontinence complaints. Recovery process was related to the elevation of bladder neck via left-sided sutures inserted in the previous operation and probable fibrosis on the right side.

\section{Conclusion}

Laparoscopic Burch colposuspension is an effective and minimally invasive alternative to mesh surgery. However, some complications

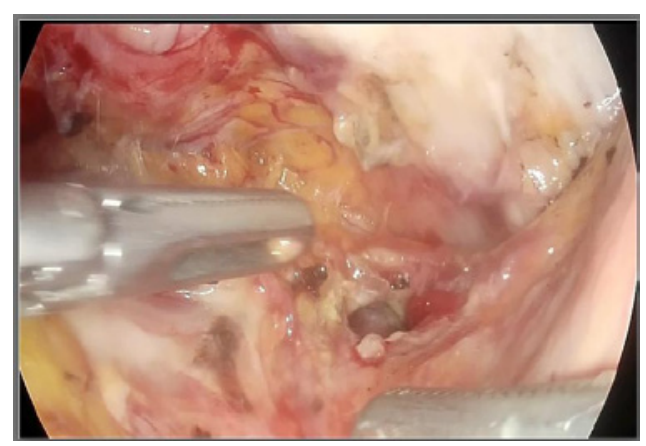

Figure 1: A 1, $5 \mathrm{~cm}$ defect localized on the right anterolateral wall of the bladder.
Austin J Obstet Gynecol - Volume 4 Issue 4 - 2017

Submit your Manuscript | www.austinpublishinggroup.com

Kinay et al. @ All rights are reserved
Citation: Kinay T, Ensari T, Unsal M, Acıkgoz O, Altinbas SK and Tapisiz OL. Occult Bladder Perforation with Atypical Localization: A Complication of Laparoscopic Burch Colposuspension. Austin J Obstet Gynecol. 2017; 4(4): 1085. 


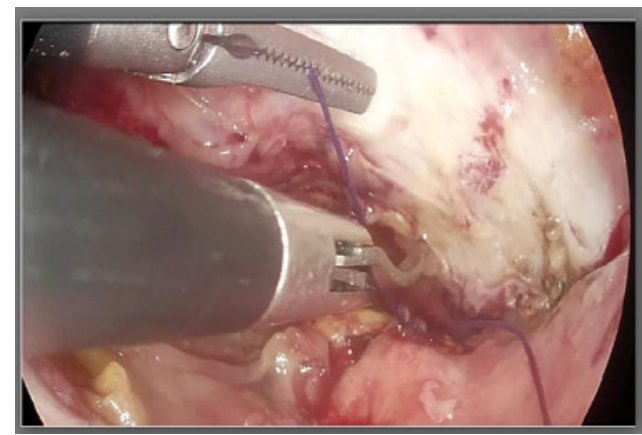

Figure 2: Bladder perforation was repaired via laparoscopic sutures.

may occur due to this technique. Clinicians should keep in mind that a laceration in an atypical localization might be present, and detection of the defect via cystoscopy can be very difficult in such a case. Diagnostic laparoscopy with a more careful cystoscopy examination will be useful. Minimally invasive surgery is a convenient approach for both Burch colposuspension and management of its complications in experienced hands.

\section{References}

1. Dean NM, Ellis G, Wilson PD, Herbison GP. Laparoscopic colposuspension for urinary incontinence in women. Cochrane Database Syst Rev. 2006.

2. Lapitan MCM, Cody JD, Mashayekhi A. Open retropubic colposuspension for urinary incontinence in women. Cochrane Database Syst Rev. 2017.

3. Jelovsek JE, Barber MD, Karram MM, Walters MD, Paraiso MF. Randomised trial of laparoscopic Burch colposuspension versus tension-free vaginal tape: long-term follow up. BJOG. 2008; 115: 219-225.

4. Ankardal M, Ekerydh A, Crafoord K, Milsom I, Stjerndahl JH, Engh ME. A randomised trial comparing open Burch colposuspension using sutures with laparoscopic colposuspension using mesh and staples in women with stress urinary incontinence. BJOG. 2004; 111: 974-981.
Austin J Obstet Gynecol - Volume 4 Issue 4 - 2017

Submit your Manuscript | www.austinpublishinggroup.com Kinay et al. (C) All rights are reserved
Citation: Kinay T, Ensari T, Unsal M, Acıkgoz O, Altinbas SK and Tapisiz OL. Occult Bladder Perforation with Atypical Localization: A Complication of Laparoscopic Burch Colposuspension. Austin J Obstet Gynecol. 2017; 4(4): 1085. 